\title{
Developments in Power Generation and Transmission Infrastructures in China
}

\subsection{Introduction}

The China electricity industry started in 1882. By 1949, the country had a small electricity system with $1.85 \mathrm{GW}$ installed capacity and $6,500 \mathrm{~km}$ of transmission lines. The electricity system expanded rapidly over the last five decades or so. By the late 1990s, the expansion fundamentally changed the nationwide electricity shortage. The China electricity system now is the world's second largest with 338GW-installed capacity and generation was $1478 \mathrm{TWh}$ in 2001. Official statistics show power consumption growth in China averaging $7.8 \%$ annually throughout the 1990s. Starting from the second half of 2002, China electricity supply was far short of demand because of dry spells that decreased hydroelectric supply, a generator shortage, and unexpected demand from energy-intensive industries. During this period, twenty-one provinces, municipalities, and autonomous regions in China suffered large-scale electricity shortages. Some had to implement load shedding to limit electricity consumption to avoid blackouts. By the end of 2005, China accumulated a total installed capacity of $508 \mathrm{GW}$. China's electricity output reached 2474.7TWh. China Electricity Council (CEC) estimated that the electricity supply and demand would reach equilibrium in 2007. According to the International Energy Agency, to meet rapidly growing electricity demand, China will invest a total of nearly 2 trillion U.S. dollars in electricity generation, transmission, and distribution in the next 30 years. Half of the amount will be invested in power generation; the other half will go to transmission and distribution [1].

Developing fuel sources for electricity generation has been difficult due to the fact that energy resources are predominantly located in the west and north of the country, while large economic and load centers are in the east and south of China. Transportation of energy adds tremendous costs to electricity supply. This has been especially so in the case of already expensive hydropower development.

China's energy policy is shifting towards diversification of energy resources because heavy coal use has had an adverse impact on the environment. Developing hydroelectricity serves the government strategy to develop the poorer western region. Moreover, the government is also ready to develop natural gas as fuel for power generation. Close to 10GW natural gasfired generation capacity was developed from 2001 to 2005, including 7.93GW in eastern China using piped gas from Xinjiang and 2GW in Guangdong Province using LNG shipped from Australia. Integrated gas combined cycle (IGCC) technology is a type of electricity generating technology with high efficiency and low pollution that can meet the need for environmental protection. Efficiency of electricity generation can reach more than $60 \%$. Research on this key technology has been started in China. It includes the technologies of the IGCC process, coal gasification, coal gas cleaning, gas fuelling engines and residual heat systems. 
In 2005, the per kWh electricity on average in the coal-fired plants consumed 374.00gce. The larger the generation unit, the smaller the amount of coal consumption per unit of electricity generated. For unit generating capacity of $300 \mathrm{MW}$, the coal consumption rate is at $341.88 \mathrm{~g} / \mathrm{kWh}$; for those units of $600 \mathrm{MW}$ capacity, the number is $326.34 \mathrm{~g} / \mathrm{kWh}$. For supercritical units, the rate is at $320.58 \mathrm{~g} / \mathrm{kWh}$, comparable to the OECD levels. In terms of power transmission losses, the average figure is about $7 \%$ for the national power grids.

In China, much of the renewable resources are in regions with low energy demand, such as Inner Mongolia and Xinjiang. Because the need for electricity could be hundreds or thousands of km away, there are serious questions about the ability of China's already shaky transmission system to handle the movement of these large amounts of electricity. Where transmission capacity is not sufficient, it will be impossible to invest in transmission lines. In fact, some laws limit the amount of renewable electricity that can be supplied to the local grid because of concerns about the additional burden on the transmission system.

Though use of hydro and nuclear power is growing, coal will still provide the majority of China's energy needs in 2030. Whatever the fuel mix, if economic growth in China stays on course, China is likely to account for $25 \%$ of the world's increase in energy generation in the next 30 years.

The China electricity policy is to achieve sustainable development of the power industry; to place equal emphasis on development and energy conservation; to attach great importance on environmental protection; and to deepen structural reform in the power sector. For the transmission grid, it plans to build West-to-East power transmission corridors with nationwide interconnection. The policy is to enhance regional and provincial grids interconnection and continue rural network construction and innovation. In addition, it strengthens construction of systems for protection, communication and automatic control. For power generation, China promotes energy conservation priority and the development of hydroelectric power. There are plans to optimize thermal power development and develop nuclear power and renewable energy steadily.

In October 2005, the "Communist Party of China (CCP) Central Committee's Proposal on the Formulation of the 11th 5-year Plan for National Economic and Social Development" was released. According to this, the China power industry should continue resource saving and environment friendly development, and realize sustainable development. The Proposal demonstrates that up to 2010, the China electric power industry will increase its installed capacity from 570 to $870 \mathrm{GW}$. Investment of 125 billion US\$ and 100 billion US\$ will be needed in the power generation and power grid construction, respectively.

\subsection{Main Transmission Projects}

In China, the distribution of energy resources is quite uneven geographically. $82 \%$ of coal deposits are scattered in the north and southwest. $67 \%$ of hydropower is concentrated in the southwest. Therefore the north and west are called as the energy bases in China. But $70 \%$ of energy consumption is concentrated in the central and coastal areas of the country. 
So transmitting electric power from the energy bases is one of the ways making up the deficits of energy in the central and coastal areas, and it is imperative to develop regional power systems interconnection. In addition, the comprehensive interconnection benefits, such as load leveling, emergency back up, peak load savings, improving operation performance can also be obtained. The construction of Three Gorges Hydropower Project has pushed the implementation of nationwide interconnection project. The nation's total installed capacity has reached around $510 \mathrm{GW}$ and $500 \mathrm{kV}$ AC lines or HVDC lines have interconnected all the regional electric power systems in the year of 2005. The main interconnection projects are shown in Table 13.1 [1].

In order to achieve a continual development in China, the policy, which is "Developing hydropower actively, thermal power optimally, nuclear power appropriately, renewable energy suited to local conditions", will be pursued.

\begin{tabular}{|l|l|l|l|}
\hline $05 / 2001$ & $\begin{array}{l}\text { North- East China } \\
\text { Power Grid } \\
\text { (NECPG) }\end{array}$ & $\begin{array}{l}\text { North China } \\
\text { Power Grid } \\
\text { (NCPG) }\end{array}$ & $\begin{array}{l}\text { Transmitting power } \\
\text { from NECPG to NCPG } \\
\text { through 500kV AC }\end{array}$ \\
\hline $10 / 2001$ & $\begin{array}{l}\text { East China } \\
\text { Power Grid } \\
\text { (ECPG) }\end{array}$ & $\begin{array}{l}\text { Fujian Provincial } \\
\text { Power Grid }\end{array}$ & $\begin{array}{l}\text { Exchange power } \\
\text { through 500kV AC }\end{array}$ \\
\hline $05 / 2002$ & $\begin{array}{l}\text { Central China } \\
\text { Power Grid } \\
\text { (CCPG) }\end{array}$ & $\begin{array}{l}\text { Sichuan \& } \\
\text { Chongqing } \\
\text { Power Grid }\end{array}$ & $\begin{array}{l}\text { Exchange power } \\
\text { through 500kV AC }\end{array}$ \\
\hline $06 / 2003$ & $\begin{array}{l}\text { Central China } \\
\text { (Three Gorges) } \\
\text { Power Grid }\end{array}$ & $\begin{array}{l}\text { East China } \\
\text { Power Grid } \\
\text { (ECPG) }\end{array}$ & $\begin{array}{l}\text { Transmitting power } \\
\text { from Three Gorges to } \\
\text { ECPG (3000MW) } \\
\text { through } \pm 500 \mathrm{kV} \text { DC }\end{array}$ \\
\hline $09 / 2003$ & $\begin{array}{l}\text { North China } \\
\text { Power Grid }\end{array}$ & $\begin{array}{l}\text { Central China } \\
\text { Power Grid }\end{array}$ & $\begin{array}{l}\text { Exchange } \\
\text { through 500kV AC }\end{array}$ \\
\hline $06 / 2004$ & $\begin{array}{l}\text { Central China } \\
\text { (Three Gorges) } \\
\text { Power Grid }\end{array}$ & $\begin{array}{l}\text { South China } \\
\text { Power Grid } \\
\text { (SCPG) }\end{array}$ & $\begin{array}{l}\text { Transmitting power } \\
\text { from Three Gorges to } \\
\text { SCPG (3000MW) } \\
\text { through } \pm 500 \mathrm{kV} \text { DC }\end{array}$ \\
\hline $07 / 2005$ & $\begin{array}{l}\text { Central China } \\
\text { Power Grid }\end{array}$ & $\begin{array}{l}\text { West China } \\
\text { Power Grid } \\
\text { (WCPG) }\end{array}$ & $\begin{array}{l}\text { Exchange power } \\
\text { through Back-to-back } \\
\text { DC (360MW) }\end{array}$ \\
\hline
\end{tabular}

Table 13.1 Main Power Transmission Projects

\subsection{Power Grid Development}

With the principle of unified planning for power grid development, China is making great efforts to implement coordinated growth of power grids at all levels including regional and provincial power grids, as well as those between power grids and power sources. 
Now, China is planning to build a state bulk power grid with voltage level of $1000 \mathrm{kV}$ HVAC and $\pm 800 \mathrm{kV}$ HVDC. From 2008 to 2020 , the HVAC and HVDC hybrid grids will result in trans-regional, large capacity, long-distance and low loss transmission, as well as optimizing the resources allocation to a larger scope and relief the stress of power shortage [2].

Large amount of power will be transmitted from coal power base and hydropower base facilities in the north and southwest area to central and coastal areas of the country through HVAC and HVDC hybrid grids.

\subsubsection{Trans-Regional Power Transmission}

With efforts to strengthen Trans-regional power resource allocation, China is expanding the scale of Trans-regional power transmission to expand Trans-regional power transmission capacity. One of the measures is to speed up the upgrading of existing $500 \mathrm{kV}$ grids by advanced transmission technology.

\subsubsection{Construction and Operation of HVDC Power System}

There are six long-distance HVDC lines in operation in China. Through these HVDC lines, the power from the southwest area and Three Gorges is transmitted to South China and East China. The total transmission capacity of these HVDC lines is 15GW. In July 2005, the backto-back DC project between Northwest power grid and Central power grid was put into operation. The exchange power is 360MW.

The HVDC projects under construction or in planning are as follows:

(1) The back-to-back $\pm 500 \mathrm{kV}$ DC project between Northeast power grid and North power grid, with transmission capacity 1,500MW. It is be commissioned around 2008.

(3) The project of $\pm 500 \mathrm{kV}$ HVDC from Ningxia in North-west China to Tianjing in North China. The transmission capacity is $3000 \mathrm{MW}$. It will be available around 2008.

(4) The project of two $\pm 500 \mathrm{kV}$ HVDC lines on one tower from Central China to East China. The transmission capacity is 6000MW. It will be available around 2009.

(5) $\pm 500 \mathrm{kV}$ HVDC project from Hulunbeier Coal base in Hailongjiang province to Liaoning province in Northeast China. Transmission capacity is 3,000MW, and it will be available around 2009-2010.

(6) $\pm 800 \mathrm{kV}$ HVDC project from Yunnan province to Guangdong province in South China. Transmission capacity is 5,000MW, and it will be available around 2009-2010.

(7) There will be three $\pm 800 \mathrm{kV}$ HVDC projects for Xiluodu and Xiangjiaba hydropower station in south-west China, in which two will go to East China and one to Central-China. The transmission capacity of each project is 6,400MW. They will be commissioned from 2011 to 2016. 
(8) $\pm 800 \mathrm{kV}$ HVDC projects from Jingping hydropower station in southwest China to East China. Transmission capacity is 6400MW, and it will be available around 2013.

(9) There will be $\pm 800 \mathrm{kV}$ HVDC projects for Hulunbeier Coal base, in which one will go to Liaoning province in Northeast China and another will go to North China. The transmission capacity of each project is 6,400MW and it will become available from 2015 to 2020.

\subsubsection{0kV and 1000kV AC Transmission and Substation Project}

In September 2005, the first $750 \mathrm{kV}$ transmission project was commissioned in China. This project is regarded as a sample project. It is comprised of $146 \mathrm{~km}$ transmission from Guanting of Qinghai province to East Lanzhou of Gansu province in North-west China. In 20072008 , a $750 \mathrm{kV}$ power grid located in North-west China began to take shape. The $750 \mathrm{kV}$ transmission and substation project is of significance to acceleration of technology innovation on the power grid in China and the promotion of construction on the HVAC power grid, respectively.

In 2008 , the first $1000 \mathrm{kV}$ AC transmission and substation project, as a testing and sample project, will be commissioned. It is the tie line between Central China power grid and North China power grid. The length of this line is about $650 \mathrm{~km}$.

\subsubsection{Construction and Operation of Urban and Rural Power Grids}

With urban and rural power grids construction and renovation, the grid structure is better reformed and the transmission line losses are decreased by a large amount. The reliability is improved greatly, with availability of urban and rural electrical power kept above $99.89 \%$ and $99.0 \%$, respectively.

\subsubsection{Enhancing international cooperation}

Due to the policy of "opening up", China has built and continued strategic partnership with well-known enterprises in many countries and regions in the world. This has led to international cooperation in the field of power grid construction, mechanism reform, technical exchange, environmental protection, etc.

\subsubsection{Improving environmental protection}

China is giving close attention to harmonious development of power grid strengthening and environmental protection. High attention is being paid to protect the environment and landscape, water source and reduce waste. The government encourages development of Renewable energies and clean power, such as wind power in some islands of coastal areas, such as Xinjiang and Inner Mongolia, etc.

\subsubsection{Opportunities and Challenges of National Grid}

\subsubsection{Strong growth in power demand}

Despite rapid growth of the power industry as a result of the huge population, the per capita installed capacity and power consumption in China is only $0.3 \mathrm{~kW}$ and $1,452 \mathrm{kWh}$, respec- 
tively, which is less than half of the world average and 1/6 to $1 / 10$ of that in industrialized countries. It infers that a huge development of power load will take place in the future. China is now building a well-off society in an all-round manner. The estimated annual GDP will reach 4000 billion USD in 2020. Sufficient power supply is necessary for fast and sustainable economic growth. It is expected that nationwide power consumption will reach $4,600 \mathrm{TWh}$ per annum, demanding total installed capacity of $1000 \mathrm{GW}$ by the year of 2020 . It means that, in the following 15 years, the annual incremental capacity will be more than $33 \mathrm{GW}$ with annual growth of power consumption of $160 \mathrm{TWh}$.

\subsubsection{Economic performance of HV transmission}

According to primary investigation, for same transferred power and transmission distance, the unit cost of $1000 \mathrm{kV}$ HVAC transmission is $73 \%$ of that of $500 \mathrm{kV}$ HVAC transmission. The unit cost of $\pm 800 \mathrm{kV}$ HVDC transmission is $72 \%$ of that of $\pm 500 \mathrm{kV}$ HVDC transmission. The advantage of $\mathrm{HV}$ in the transmission of huge quantities of electricity over long distances is apparent.

\subsubsection{Construction of HV Transmission Grid}

The State Grid is determined to construct HVAC pilot transmission lines and HVDC projects in coming years. Once the construction of the first series of HV projects is successful, the State Grid will promote extensive application of $\mathrm{HV}$ technology to construct a $\mathrm{HV}$ backbone network.

\subsubsection{1000kV HVAC pilot project}

$\mathrm{HV}$ transmission is an innovation of technology, and also a big challenge. All work on HV should be initiated from a practical pilot project. The purpose of building a pilot project is to test performance of the HV system and its equipment, accumulate experiences for HV research and operation, and improve the level of technology in HV equipment manufacture and power transmission.

The State Grid has completed the selection of pilot projects and the feasibility studies. The system scheme is provisionally determined. In this scheme, the total length of the HV transmission line is about $650 \mathrm{~km}$, including two HV substations and one switchgear station. The advantages of the pilot scheme include easy implementation of engineering construction, the wide testing of both the HVAC system and its devices, and extensive guidance for future application of HVAC in China.

\subsubsection{Outgoing HVDC transmission line of Jinshajiang River}

The advantage of HVDC is to transmit large quantities of power over very long distance. In China, $\pm 800 \mathrm{kV}$ DC will be mainly used to transmit large capacity over very long distance from huge hydropower bases and thermal power bases. Other application involves some long distance transmission projects with little support of power supply along the transmission line. There is abundant hydro resource along the Jinshajiang River. The exploitable hydropower is about $90 \mathrm{GW}$, with annual power generation of $500 \mathrm{TWh}$. At the first stage, there are two hydropower stations, viz. Xiluodu and Xiangjiaba. The total installed capacity of the 
two hydropower stations is $18.6 \mathrm{GW}$, which is $0.4 \mathrm{GW}$ higher than that of the Three-Gorges project. In order to reduce transmission cost and power loss, and save transmission corridors for future development, the State Grid is determined to develop the scheme using 3 circuits at $\pm 800 \mathrm{kV} \mathrm{UHVDC}$, one for the Central China Grid, the other two for East China. The total length of these UHVDC transmission lines is about $4,820 \mathrm{~km}$ with transmission capability of $6.4 \mathrm{GW}$ over each circuit. At present, the feasibility study for the above project is on going. As a schedule, the construction of the first UHVDC transmission line will be started in 2008. It will be put into operation in 2011.

\subsubsection{Prospect of national HV grid}

In order to optimize allocation of energy resource, exploit the large-scale coal bases at Shanxi, Shannxi, Inner Mongolia and Ningxia, and harness remote hydropower in Southwest China, the State Grid will construct a nationwide HV transmission grid. At first, the State Grid will construct 1000kV HVAC transmission that links North Grid and Central China Grid. Then it will expand the 1000kV HV synchronous grid to East China; finally accomplishing a strong HVAC network that connects the North-Central--East China Grid. Combined with the HVAC and HVDC power grid for hydropower transmission in southwest China, it will form a strong HV grid that covers large energy bases and load centers. The total transmission capability of the HV and trans-regional grid will exceed 200GW.

\subsubsection{South China HVAC/HVDC Hybrid Grid}

\subsubsection{The rapid growing-up of South China Power Grid}

The South China Power Grid covers five provinces: Guangdong, Guangxi, Yunnan, Guizhou and Hainan. These provinces have an area of about one million square $\mathrm{km}$ and a total population of 220 millions. From 1980 to 2004, the total installed capacity of the South China Power Grid has increased by a factor of 10, up to $80.27 \mathrm{GW}$ (excluding that of Hong Kong and Macau). Annual generating capacity has increased by 14.3 times, up to 383.2TWh [2]. Total electricity consumption has increased by 15.6 times, up to $389.1 \mathrm{TWh}$, accounting for $17.9 \%$ of the total in China.

In August of 1993, the power grids of Guangdong, Guangxi, Yunnan and Guizhou began interconnected operation. There was only one transmission passage from West to East; the transmission capacity was 600MW with sales of $2.1 \mathrm{TWh}$ /annum. Up to 2005, a solid framework of nine $500 \mathrm{kV}$ passages from west to east had been constructed, $6 \mathrm{AC}$ lines and $3 \mathrm{DC}$ lines with total capacity of $11.75 \mathrm{GW}$. The annual trading amount reached $44.7 \mathrm{TWh}$. These two figures have increased by 19.6 and 21.3 times accordingly. The west power ratio in Guangdong dispatchable total energy increased from 3\% to $30 \%$. The total length of transmission lines above $220 \mathrm{kV}$ is $39,283 \mathrm{~km}$ and the total transformer capacity $140.05 \mathrm{GVA}$, which is 3 times and 5.5 times, respectively, from the beginning of networking.

\subsubsection{The unique features}

The South China Power Grid is the one that has the most complicated structure and connections, the highest science and technology level, and at the same time, is the most difficult to operate in China. The grid can be summarized as follows: 
1. Long Transmission Distance and Large Capacity

The distribution of power resources and the load in the southern area are quite out of equilibrium. This characteristic requires implementing power transmission from west to east to optimize energy utilization. The distance of each of the nine long transmission passages from west to east is around $1000 \mathrm{~km}$ and one pole capacity of the DC lines is 3000MW.

2. Multi DC in feeds

DC channels and 6 AC channels of $500 \mathrm{kV}$ from Tianshengqiao to Guangzhou Province and Guizhou Province to Guangzhou Province are operated in parallel. Three DC lines connect Three Gorges to Guangdong, TIanshenqiao to Guangdong and Guizhou to Guangdong, simultaneously supplying power to the Guangdong $500 \mathrm{kV}$ network. The electric distances between converter stations are very short.

3. Various Types of Power Sources

There are various power sources within the grid, such as hydropower, coal fired power, nuclear power, pumped storage and storage by hydropower, oil-fired power, gas-fired power, wind power. The capacity of single units of nuclear and thermal power is quite large. Among those, the capacity of single unit of Lingao Nuclear Power Plant and Daya Bay Nuclear Power Plant is as large as 1,200MW.

4. Wide application of new technologies

The South China Power Grid has centralized many advanced power transmission techniques in the world. The primary techniques include DC power transmission, electric trigger and light trigger of silicon controlled valve, thyristor controlled series capacitors, fixed series capacitors, high-altitude compact circuitry, and superconductor cable, etc. The secondary techniques include the largest and most advanced security stability control system in China, as well as the wide area measuring system which covers the whole grid and the online stability analysis and pre-decision system that has been primarily established

\subsubsection{The challenges}

For safe operation, the South China Power Grid is confronted with many risk issues.

\section{Outstanding problems of grid stability}

This problem consists of four aspects. The first aspect is power-angle stability. Once fault trips occur on AC transmission lines, it is possible to destroy power-angle stability and voltage stability because of large-scale power displacement. For a multi-feeding DC system, if the AC transmission problems cannot be isolated timely, it is possible that many DC lines are also disturbed that will destroy the system stability. The second aspect is dynamic stability. The west-to-east span of the South China Power Grid is nearly $2000 \mathrm{~km}$, the cross-area oscillation mode has relatively low damping, so it is a long-standing problem to control and eliminate the low-frequency oscillations. The third aspect is voltage stability. With rapid growth of load and inter-grid power transmission and receiving, as well as the formation of the multi infeed of several DC loops into Guangdong power grid, the problem of voltage stability has become more and more exacting, and this problem is quite unique. The fourth 
problem is thermal stability. During high peak load in summer, some circuits and equipment are nearly operated to the limit of thermal stability. In this case, it is possible that N-1 outage can threaten the security of equipment and the systems.

\section{The control systems security and stability}

Once the grid has serious faults, only if the security and stability systems takes measures of cutting-off transmission and load can the grid remain stable. It is technically very difficult to operate such a large-scale AC/DC stability control system, and also as the system is very sophisticated, it is very possible to make mistakes or for the protection fail to operate correctly.

\section{The dynamic voltage support}

Additional capacitors have been installed at many stations of the Guangxi Grid, and feasibility studies on installing SVC or SVG are still ongoing. It is estimated that after the Qinzhou power plant and the Fangcheng Bay power plants in Guangxi Province are connected to the grid of $500 \mathrm{kV}$, the stability level for dynamic voltage stability may be considerably improved.

By means of various advanced technologies and management measures, stable and safe operation of the South China AC/DC hybrid power grid may be successfully enhanced.

\subsubsection{Future of South China Power Grid}

General planning of development of the South China Power Grid is to insist on scientific development to meet the need of power consumption for development of the economy and daily life; to meet the need of safe reliable and stable operation of the power system, to realize large-scale optimization of energy resources, to constantly improve technology and management level of the power system, to lower cost of the power system, to realize sustainable development, and to construct the South China Power Grid into a uniformed, open, reasonably structured, reliable modern power grid. To achieve this, the following priority areas are implemented.

\section{Speed up power grid development and technology upgrading}

After two years deep investigation and research, HVDC application in South China has a good foundation. The reasons of HVDC application depend on power grid characteristic; depend on the need of increasing west to east transmission capacity as well as solving the problem of transmission passage space and land. It will effectively solve the problem of short circuits at load center-Guangdong Power Grid; it will effectively enhance the capability of multi-infeed of DC lines to promote safe and reliable operation of the power system. For the period 2010-2015, the first phase of $\pm 800 \mathrm{kV}$ DC lines from Yunnan to Guangdong are planned to be constructed of length $1600 \mathrm{~km}$ and $5000 \mathrm{MW}$ capacity. The project will be put into operation before June of 2009 .

\section{Optimize the allocation of power resources}

From now on, the development of generation resources should be adjusted to satisfy requirements of load and environment protection. That is to optimize the coal-fire electric power, to develop hydroelectric power actively, to accelerate the speed of nuclear power 
development, to develop natural gas and pump-storage for electric power reasonably, to develop new energy in accordance with regional features, and to construct peak load power plant in areas of intense load. It is planned that during the "11 th 5-years Plan", newly installed capacity of the resources will be 67GW; while in 2010, the total capacity will reach $147.5 \mathrm{GW}$. During the following 10 years, the new installed capacity will be 95GW. By the year 2020, total installed capacity will be 240.8GW. It is estimated that the average power per capita will be about $1 \mathrm{~kW}$.

\section{Increase power transmission}

During 2010-2015, according to 11th 5-year Plan, west energy transmitted to east will increase 11.5GW to 13.5GW. By 2010, the transmission capacity from west to east will amount to 22.38GW-24.38GW. It is planned that during 2011-2030, 33GW-38GW energy will be added to the sum, that is, by the year of 2030, the total capacity of west to east transmission will reach 55GW-62GW.

Meanwhile, the South China Grid is actively promoting power cooperation with supply energy to Vietnam, Thailand and Burma. The South China Grid enhances cooperation on electric power with Hong Kong and Macau.

\subsubsection{Wide Area Measurement System (WAMS)}

With the development of GPS, computer and communication technology, the prototype of phasor measurement unit (PMU) was first developed in United States in early 1990s. It attracts great attention in China since its birth [4,5].

The installation of PMU in Chinese power grid can be dated back to 1995. The China Electric Power Research Institute (CEPRI) introduced a system that had the function of phasor measurement and was commissioned as PMU in the Chinese power grid. From 1995 to 2002, about 30-40 systems were installed and the main stations of WAMS were established in East China, South China, Northwest and Sichuan Power grid and State Power Dispatching Center (SPDC) successively. Such systems adopted modem as communication media and internal communication protocol where the data can be uploaded to the main station of WAMS every second. The installed system successfully recorded the dynamic process of low frequency oscillation that occurred in the Chinese power grid several times which revealed the significant value of synchronized phasor measurement technology in the area of power system dynamic monitoring and also pushed the development of prototype of PMU of Chinese manufacturer.

At the end of 2002, Chinese manufacturers have the commercial product of PMU that have been commissioned in the Chinese power grid since 2003. By the end of 2006, over 300 PMUs had been installed, which are mainly distributed at substations and power plants of the $500 \mathrm{kV}$ and $330 \mathrm{kV}$ voltage level. 7 regional WAMS are constructed in SPDC and North China, Northeast, Northwest, East China, Central China, South China power grids. 6 provincial WAMS are established in Jiangsu, Shandong, Guangdong, Guizhou, Yuannan and Shanxi power grids. Moreover, real time data exchange is realized among SPDC, North China and Northeast WAMS. 
Since there are different approaches to achieve phasors and more than one manufacturer, a Chinese standard on PMU and WAMS was drafted by the State Grid Company and manufacturers in 2003, and finally issued in 2005. The standard supplements transmission protocol of historical data on the basis of IEEE Std 1344-1995 (R2001). The synchrophasor standard provides a technical specification for manufacturers and allows interchange of data between a wide variety of users of both real time and offline phasor measurements, which is of great importance for Chinese WAMS implementation. The blackouts that occurred worldwide in recent years also confirm the urgent needs of WAMS. Therefore, for the next five years, all $500 \mathrm{kV}$ substations and $300 \mathrm{MW}$ and above power plants in the Chinese power grid will install PMU according to $11^{\text {th }}$ 5-year Plan.

\subsubsection{WAMS in China}

In China the main station of WAMS is located at the regional or provincial dispatching center and composed of advanced application station, database server and data concentrator. It can be seen that the advanced application station retrieves data from data concentrator via LAN instead of Ethernet, which reduces time delay for the data. From this point of view, the data concentrator here is not the same as that in IEEE STD C37.118 although the names are same.

The data concentrator in the main station is one of key points in WAMS. Currently, some data concentrators already contain 5000 phasor measurements and the storage rate of the phasor is $100 \mathrm{~Hz}$. With the fast development of WAMS, how to construct the data concentrator with 100 PMUs and 10,000 phasor measurements and provide corresponding high-speed storage and enquiry technology is also a challenging work.

The functions of advanced application station include visualization of dynamic process and available transmission capacity, wide-area data recording and playback, and on-line low frequency oscillation analysis. Due to the long transmission distance and weak interconnection, low frequency oscillation is a quite severe problem in China. As an only tool catching the oscillation, WAMS played an important role in low frequency oscillation identification and control in China in 2005 and 2006. New identification and preventive control methods are undergoing development.

WAMS opens a new path for power system protections, especially for backup protections (the time delay of backup protections makes it possible to acquire and deal with the phasor data of power systems). Some research works has been launched into this area. To handle the cascading trip problem, the fundamental solution is to monitor the load and try to identify whether the overload is caused by flow transferring or internal fault. If flow transferring does occur in the system, then block the backup relay before the thermal limit of the line has been reached.

It should be pointed out that the philosophy of main protection should not be changed with the advent of WAMS. On one hand, acquisition of phasor measurements will inevitably increase the time delay of trip signal that has adverse impact to system component and stability. On the other hand, the introduction of WAMS information makes the main protection more complex that might correspond to lower reliability. 


\subsection{Diversity in Power Generation}

Based upon the current situation of resource storage and the requirements of increasing power load in China, the basic principles of power supply is to develop hydropower vigorously, optimize the development of coal-power, promote the construction of nuclear electricity, develop natural gas generation steadily and speed up the exploitation of new energy resources generation. By 2020, it is estimated that the total capacity of conventional hydropower will reach $240 \mathrm{GW}$, nuclear $40 \mathrm{GW}$, gas $45 \mathrm{GW}$, new energy sources $10 \mathrm{GW}$, the other 600GW is still depended on the coal generation. Coal-fired power generation and hydropower still play a leading role in the future. Table 13.2 shows the generation mix in 2010 and 2020.

\begin{tabular}{|l|l|l|}
\hline & \multicolumn{1}{|c|}{2010} & \multicolumn{1}{c|}{2020} \\
\hline Total installed Capacity [GW] & $543-559(100 \%)$ & $865-947(100 \%)$ \\
\hline Coal & $338-384(62-69 \%)$ & $509-661(56-69 \%)$ \\
\hline Oil & $3-4(1 \%)$ & $1-6(1 \%)$ \\
\hline Natural gas & $25-28(5 \%)$ & $43-46(5 \%)$ \\
\hline Hydro power & $132-154(24-28 \%)$ & $191-240(22-25 \%)$ \\
\hline Nuclear power & $9-15(2-3 \%)$ & $31-40(3-4 \%)$ \\
\hline Renewable sources & $3-7(1 \%)$ & $11-13(1-3 \%)$ \\
\hline
\end{tabular}

Table 13.2. Outlook of Generation Components from 2010 to 2020 [6]

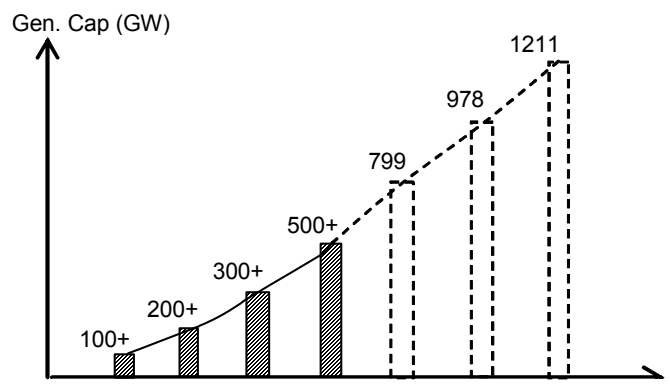

Fig. 13.1. Generation Capacity in China

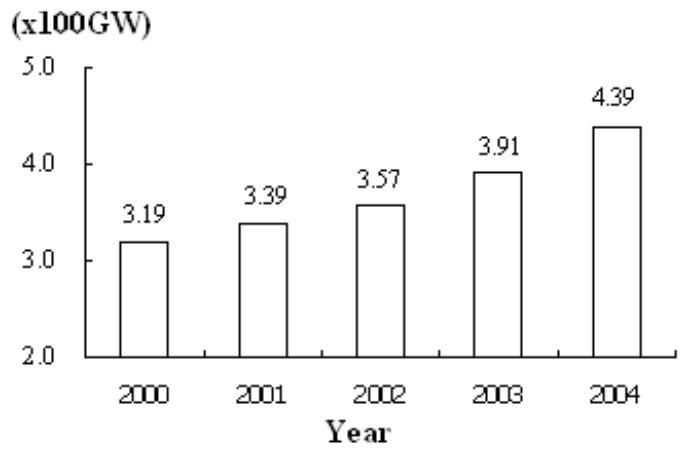

Fig. 13.2. Annual installed capacity in China since 2000 
Figures 13.1, 13.2, 13.3 and 13.4 show generation capacity in China from 1990s to 2020, the annual installed capacity in China from 2000 to 2004 and utilization hours of coal-fired power from 2000 to 2004, generation capacity growth, demand growth and utilization hours of cola-fired plants respectively $[7,8]$.

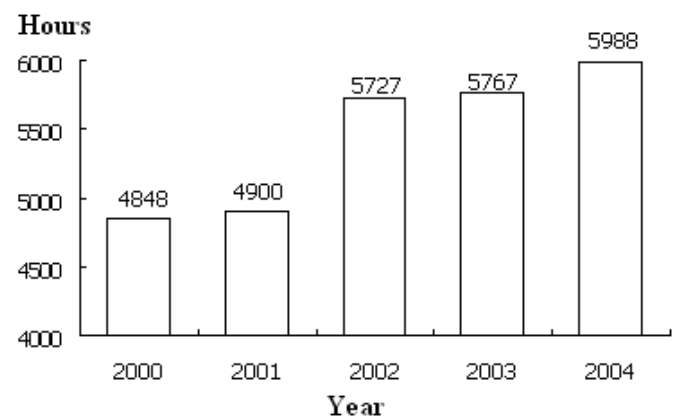

Fig. 13.3. Utilization hours of coal-fired power since 2000

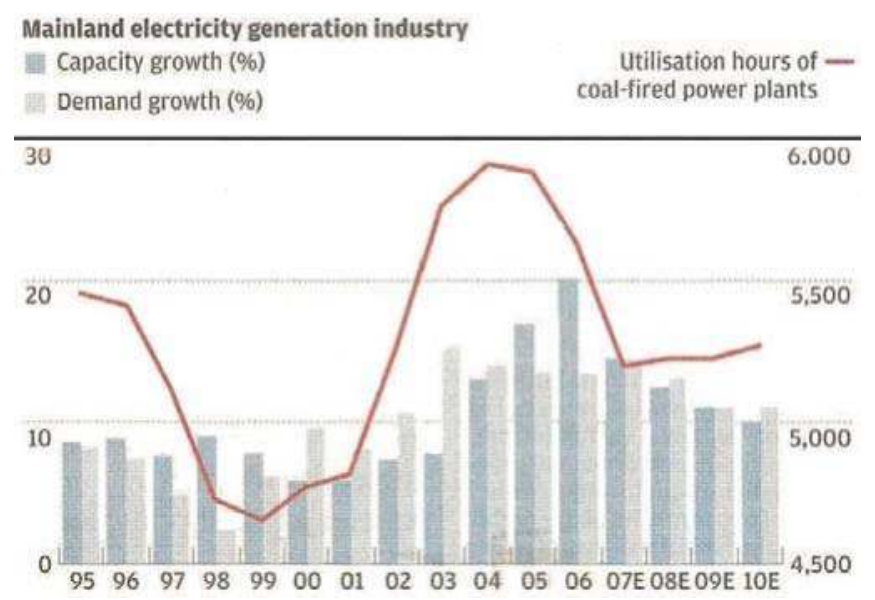

Source: J P Morgan [7]

Fig. 13.4. Generation capacity growth, demand growth and utilization hours

\subsubsection{Higher Requirements on Resources Exploitation}

To meet the future demand of increased power load, a sufficient supply of primary energy source should be guaranteed. There are three features of primary energy in China, i.e. a huge production but with a low quantity per capita and unbalanced in distribution. It results in higher requirements on resources exploitation. China is abundant in coal and hydro resources but lacks oil and gas. The gross potential of hydropower and the exploitable capacity rank number 1 in the world. And the coal reserves and its exploitable capacity rank number 2. But the gross oil and natural gas rank number 10 and 22 worldwide, respectively. It indicates the dominant roles of coal fired power generation and hydropower in the future power supply. However, the resource in per capita term is relevantly low and only about 
$40 \%$ of world average level. In order to provide a sustainable power supply, promote healthy development of the economy, we must increase the efficiency of power energy and promote application of energy-saving technologies. As a third feature, the primary energy bases are located conversely with those of productivity zones, i.e. areas with rich resource are far away from the developed economic zones. Two-thirds of hydropower bases are distributed in Sichuan, Tibet and Yunan, and two-thirds of coal resources are located in Shanxi, Shaanxi and Inner Mongolia. However, the economic developed zones are mostly located in the east area, consuming most of the electric power, but short of primary energy resource. It is about $500-2000 \mathrm{~km}$ from the above resource bases in the west area to the load center in east zone. Therefore, it is indispensable to accomplish huge volume power transmission over long distance.

\subsubsection{Biomass}

China is active in generating electricity based on renewables. For example, by the end of 2004, the generation-installed capacity was 2GW. Naturally, there is tens of million tons of carbon dioxide reduction. In addition to biomass, there are many wind farm, hydro and solar projects in China, and they attract investments through carbon trading. In [7], it reported that the mainland power generation sector suffered a $93 \%$ drop in profit in the first two months of the year. The profit drop reflects spiraling coal costs, a prolonged tariff freeze and rising borrowing costs, all of which have squeezed profit margins.

Although the news increases pressure on Beijing to lift tariffs to restore profitability and offer investment incentives, analysts were not optimistic of an increase any time soon because of the time it will take for inflation to fall from the 12-year high it reached in February 2008. Huadian Energy, sister firm of Hong Kong and Shanghai-listed Huadian Power International, said it would report a loss as a result of falling plant utilization and higher coal cost. Of the economy's three worst performing sectors - power generation, power distribution and oil refining - the generation sector was the hardest hit, with profit falling $93 \%$ in January and February 2008, mainland newspaper The Economic Observer reported, quoting an unnamed source.

The National Statistics Bureau said recently that the power sector as a whole had recorded a $61 \%$ year-on-year profit decline in the first two months of 2008. While electricity distribution companies suffered revenue losses because of winter storm damage they were not affected by higher coal costs, the report said. Power companies generally lock most of their coal supply through one-year contract negotiated at the start of the year. However, some agreements are not fulfilled, exposing them to the risk that coal sellers will ask for higher prices and renege on existing contracts.

"Our concern is that as long as domestic spot coal prices remain at roughly the same level, there is a growing possibility that contract coal prices may need to be revised upwards throughout the year," JP Morgan head of Asia-Pacific utilities and infrastructure research wrote in a recent research report.

With domestic spot market coal prices $40 \%$ below international level, it was projected that coal costs of locally listed mainland power producers would rise between $20 \%$ and $30 \%$ 
/year on the year in the third quarter. Analysts said unlisted power plants were believed to have fared worse than listed ones, because listed power plants were likely to be more efficient and receive priority in power sales. Figure 13.5 shows different weekly spot coal prices variations

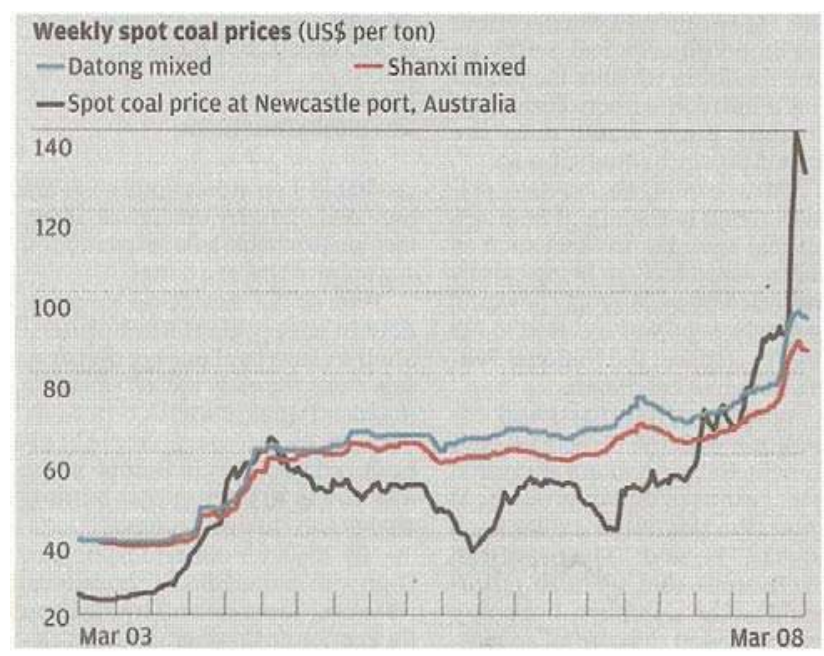

China's spot cola prices have corrected marginally by 5 to 10 RMB per ton since middle-February 2008 Australian prices have been corrected by $6.9 \%$ since mid-February 2008 , but remain $30-40 \%$ above prices within China. [7, 9]

Fig. 13.5. Different weekly spot coal prices variations

This means lower utilization rates for less efficient plants, which tends to translate into lower profits as fixed costs such as depreciation and maintenance are spread over lower output. Listed power plants also tend to be in under-supplied or balanced markets. One exception is Huadian Energy, which operates $21 \%$ of the total generation capacity of over-supplied Heilongjiang province in northeast China. The province's overall power plants utilization is forecast to fall $9.27 \%$ in 2008 to 4890 hours from 5390hours in 2007, Huadian Energy said. The company's plant utilization eased $3.39 \%$ to 5270 hours in 2007.

Meanwhile, surging interest costs have bitten into the bottom lines of companies that sough to offset higher coal costs by building more plants and generating more power. Huadian Power International, whose debt-to-equity ratio is the highest among locally listed power firms, saw a $203.88 \%$ jump in interest costs in 2007 to 1.38 billion RMB, higher than its net profit of 1.19 billion RMB.

\subsubsection{Natural Gas}

Because small internal combustion engine power generation efficiency is $24-35 \%$, the combined-cycle power generation efficiency may also reach $45-50 \%$, this figure is higher than the conventional thermal electricity generation. This fact is different from the usual idea small unit is uneconomical to use. For cold-fired power plant, the bigger unit it is, the higher the economic efficiency will be. Presently, China develops the big centralized plant as the main 
direction, however developments in distributed generation will certainly expand rapidly too due to its higher efficiency, cleaner energy and short construction time, less transmission loss and reducing possibility of blackout to improve reliability.

\subsubsection{Coal}

Coal stands the dominant position in energy consumption. In 2003, coal accounted for 70$80 \%$ of China's primary energy consumption, a reality that is doubtful to change significantly in a short time. Also, a large amount of coal is directly consumed by end -users. Coal is responsible for providing $75 \%$ of energy used in industry and $80 \%$ of household energy.

The inefficient and obsolete way of coal usage in China is responsible for the country's severe environmental pollution. Carbon dioxide emissions are the second highest in the world, while sulphur pollution in the nation is the highest in Asia. The vast majority of the pollutants, smoke and dust, sulphur dioxide, carbon dioxide, carbon monoxide and nitrogen oxides, are the result of this by coal combustion. The pollution is not only responsible for several health hazards of the country; it has also created huge economic loss.

It is seen from the above that China, if it is to ensure energy supplies and to achieve sustainable development targets, has to improve energy efficiency in order to transform coal to a clean, high-efficiency, and convenient energy resource. Therefore, clean coal technology is one of the main focuses of China's energy strategy.

\subsubsection{Low efficiency and large potential for energy saving}

China as a developing country retains its dual economic structure of agriculture and industry. In the industry sector, modem industries co-exist with traditional industries; the main characteristic of the traditional small industries is that they are decades behind in terms of modernization. These small industries use obsolete equipment and as a result energy efficiency is low while energy consumption is high. It indicates that the estimated energy consumption of major industrial products is usually $30-40 \%$ higher than that of industrialized countries; while the efficiency of main equipment is $10-20 \%$ lower than that of industrialized countries. Therefore, because the levels of energy efficiency in China are very low, there is a great potential for energy saving.

\subsubsection{Clean Coal Technology in China}

Even though China is among the largest energy producing and consuming country in the world today, due to extremely large population it has a low consumption per capita. From 1949 to 2006, the quantity of China's raw coal production had increased from 32Mt to $1212.3 \mathrm{Mt}$; crude oil, from $0.12 \mathrm{Mt}$ to $183.7 \mathrm{Mt}$; natural gas, from $7 \mathrm{Mm}^{3}$ to 50.6 billion $\mathrm{m}^{3}$; electricity power, from 4.3TWh to 1,018.0TWh. In 2006, China's energy consumption per capita was accounting for less than the one-sixth of that of US. Due to its large population, the per capita is very unlikely to increase in short time. It is estimated that it will not reach the current average level of the OECD countries until 2050. 
Coal preparation technology

Coal preparation is the most direct and practical approach to reduce pollution emission and is considered among the key interests in clean coal technology research. In 1995, the average designed wash capacity of key state-owned coal companies was $1.4 \mathrm{Mt} / \mathrm{y}$. The largest coking coal company was designed to wash $4.0 \mathrm{Mt} / \mathrm{y}$ raw coal. The largest steam coal washery was with a capacity of $20 \mathrm{Mt} / \mathrm{y}$.

\section{High-efficiency and low-pollution pulverized fuel combustion}

The majority of China's power plants apply pulverized fuel combustion technology. The investment required is relatively small, and it is suitable for the majority of types of coal in China. The main boilers for power stations that are manufactured in China are $300-600 \mathrm{MW}$ sub-critical controlled cycle or natural-cycle coal combustion boilers with combustion efficiency of $93 \%$.

The goals of China's development strategy by the year 2005 for the power plant boiler sector were to further incorporate $300 \mathrm{MW}, 600 \mathrm{MW}$ boilers combustors and combustion technology imported from foreign countries, and to develop combustors and combustion technology that have high-efficiency, good adaptability for different kinds of coal, low-load combustion stability, good performance of supply and low NOx emission. Also they had to be convenient to operate, economical and practical. Before 2010, all new power stations must adopt high-efficiency, stable combustion and low NOx emission pulverized fuel combusts as the boilers of old power stations will be gradually phased out. Also effective ways of reducing the emissions of the existing boilers will be applied.

\section{Cycle fluidized-bed boilers}

Cycle fluidized-bed coal combustion is a relatively new type of combustion technology developed in the past 20 years. It is characterized from its varied application, high combustion efficiency, and effective control of $\mathrm{SO}_{2}$ and $\mathrm{NOx}$ emissions. China started R\&D on cycle fluidized-bed boilers in the early 1980s. At present about 300 cycles fluidized-bed boilers less than 130 ton are manufactured based on domestic technology.

\section{Coal combustion for combined cycle power generation}

Coal combustion for combined cycle power generation technology includes IGCC, PFBC-CC and AFBC-CC. China started the research on pressurized fluidized-bed combustion combined cycle technology in the 1980s. Since then, a lot of research work has taken place for the design and operation of pressurized fluidized-bed combustion combined cycle technology. In 1991, the pressurized fluidized-bed combustion combined cycle power technology was listed among most important R\&D projects of the $8^{\text {th }}$ 5-year Plan (1991-1995). Since then a pressurized fluidized-bed combustion combined cycle middle-stage experiment power station, was installed and tested in Xuzhou Jiawang Power Plant. As far as IGCC technology is concerned, China has fallen far behind that of developed countries. There are no IGCC plants currently in China even though IGCC equipment will be actually operating in China in the future. 


\subsubsection{China's Clean Coal Technology and Foreign Technology}

When examining the gap between China and the developed countries in clean coal technology we should bear in mind two features. Firstly, China's technology is relatively immature and the application scale is rather small. For example, the largest production capacity of cycle fluidized-bed boiler in China is $220 \mathrm{t} / \mathrm{h}$, while in developed countries, its production capacity can be as high as $700 \mathrm{t} / \mathrm{h}$. PFBC technology stands in the 15MW experiment stage in China, while in Sweden, for example, is in the 350MW commercial demonstration stage. In the field of IGCC, 250MW demonstration equipment has been put into operation in the Netherlands and US, while in China, such technology is still in the stage of feasibility preresearch stage in demonstration plant.

Secondly, the application scope of clean coal technology is rather narrow. Even though some technology is mature, the application is very limited due to lack of effective policy instruments. As a result, the proportion of washed steam coal volume in China is less than $10 \%$, in contrast, US is $45 \%$ and European countries $75 \%$.

\subsubsection{Reasons for Falling Behind in Clean Coal Technology}

The main reasons for the existing gap in clean coal technology are the wide economic difference between China and developed countries, late environmental legislation, and the insufficient investment in clean coal technology research.

Overall deficiency in national strength

Clean coal technology is a highly capital-intensified and technology-intensified area. In US, in order to promote clean coal technology, the government provides funding to enterprises and other institutes for R\&D activities of clean coal technology. In China on the other hand, because of the weak overall economic strength, the government is unable to invest considerable amount of capital on clean coal technology research. Also even if a technology is developed, the market for such capital-intensified clean coal technology is limited. For example, investment for IGCC is twice higher than that of the same scale power plant, which is a difficult sum for Chinese investors. Finally, even though China is the biggest coal consumer in the world, the R\&D on clean coal technology began rather late.

\section{Delays due to legislation}

The market scale for clean coal technology is mainly determined by factors such as environmental legislation, enforcement of environmental laws and regulations, and public environmental awareness. As China's economy is still at a low level, and environmental legislation and enforcement are rather weak, it is very hard to stimulate innovative activities on environmental technology. Although public environmental awareness has somewhat increased, it is not strong enough to create pressures for enterprises to apply environment technology.

\section{Disjunction between RED and production}

Because of the institutional system in the area of science and technology in China, R\&D activities related to clean coal technology are primarily carried out in research institutes, which usually lack knowledge on actual needs of the industry. So, they find it difficult to develop products that meet the industrial actual needs. Also, for a technology to be com- 
mercialized, it has to go through a series of phases, such as medium scale experiment, pilot production and commercial demonstration. The lack of communication between institutions and manufacturers makes it difficult to link R\&D results in the laboratory to the production practice.

\section{Fossil Energy Protocol between the United States and China}

The US-China Fossil Energy Protocol is intended to promote scientific and technological cooperation between the United States and China in the field of fossil energy, particularly activities related to research, development, demonstration, and deployment. A complementary objective is to create opportunities for US industry and power developers in China. The Protocol was originally signed in 2000 and was renewed in 2005 for an additional five years; signatories are US Department of Energy and China's Ministry of Science and Technology. A Permanent Coordinating Group governs the Protocol, chaired on the US side by DOE's Assistant Secretary for Fossil Energy and on the Chinese side by the Secretary General of the High Technology Bureau of MOST. Outreach and communications activities are underway to introduce Chinese corporations and research groups to the latest US technologies in the areas of coal gasification, coal liquefaction, natural gas technology, coal-bed methane recovery, acid rain control technologies, and carbon dioxide capture from power plants.

\section{Analysis on China's acquisition of clean coal technology}

According to their importance, the order for various means of clean coal technology acquisition in China is as follows: equipment import, license trade, and joint ventures. Some Chinese enterprises acquire technology by means of purchasing technology service and consultancy, or by cooperative production. However, the proportion is very small. Thus, they are treated together with license trade.

\section{Importation of clean coal equipment}

Investigating clean coal technology transfer in China thoroughly and obtaining original date and information are both difficult and time-consuming. This makes the identification of what kinds of aforementioned technology having been imported in China and what technology China imported being clean coal technology an extremely difficult task. Equipment imported from industrialized countries has advantages over Chinese equipment in terms of reliability, productivity and efficiency. Foreign power generators are also superior to domestic ones in term of efficiency and reliability. The thermal efficiency of foreign industrial boilers and central-heating boilers is at least 5\% higher than that of average domestic equipment. As such, the above-mentioned equipment imported from industrialized countries is regarded as clean coal technology.

\section{Power equipment}

In 2006, the power industry consumed about $34 \%$ of all end-combustion coal in China, and there is a gap between China and industrialized countries in this sector. Therefore, it is very important for China to acquire clean coal technology from industrialized countries in order to use energy efficiently and to reduce emissions of greenhouse gases. The import of thermal power equipment occupied a relatively important position in China's thermal power industry. Desulphurisation technologies in China are mainly obtained directly from equipment imports. China has imported boilers for power stations that came mainly from US, Germa- 
ny, Russia, Japan, Australia, UK and Switzerland. US is the most important supplier, providing about $70 \%$ of China's total imports.

\section{Industrial boilers}

Industrial boilers are the most important heat-generating power equipment in China. About 500,000 industrial boilers with 1,200,000 t/ h have been used by the end of 1995 . The production output of industrial boilers in China has increased since 1990; the average incremental percentage is $10.8 \%$ per year. China is the largest producer and user of coal combustion industrial boilers in the world. The coal fired by industrial boilers occupied $1 / 3$ of the raw coal output. Because of lower operating efficiency, the actual thermal efficiency was only 60$70 \%$ during the period of the $8^{\text {th }} 5$-year Plan (1991-1995). It is $10-15 \%$ less than that of the international advanced level. This shows that energy waste in China is enormous and potential for energy saving is huge. Furthermore, more than 5 million tons of $\mathrm{SO}_{2}, 600$ million tons of $\mathrm{CO}_{2}$, large amounts of NOx and other harmful gases are emitted from coal combusted boilers every year in China. This not only causes heavy coal related air pollution in China, but also aggravates the global greenhouse effect. Therefore, it is significantly important to acquire advanced industrial boiler technology with high efficiency and low emission.

\section{Factors influencing enterprises in purchasing clean coal equipment}

There are many factors that influence enterprises decision in choosing which country, which company and what kind of clean coal technology or equipment to be imported. The major factors are as follows:

\section{Reliability of equipment}

Large utility boilers or industrial boilers are key equipment to supply power to importing enterprises. As a malfunction of the equipment causes the whole production to stop, one of the crucial concerns for the importers is the consistency of the equipment. So the history and experience of the supplier in providing reliable equipment is critical.

\section{Consumer's assessment}

In general, each industry sector has its own information communication system, by which users can evaluate the quality of certain equipment, usually in the forms of professional journals or conferences. For example, China's electricity power industry annually evaluates the reliability of electricity generation equipment, and the result is announced at a conference at the beginning of each year and in professional journals. Evaluations like the above have great effect on consumers purchasing new equipment.

\section{Applicability and advancement}

When acquiring clean coal technology, the government also considers if the technology is advanced or not. When it comes to the private sector though the prime factor is the applicability and the advancement of the technology secondary.

\section{Equipment performance}

Companies also focus on the level of automation and the easiness of operation and maintenance. As in all cases, capital cost is the most important constraint for importers, so they always balance the ratio of price and function of equipment or technology among different suppliers. 
Environmental effects of equipment

As the government takes more measures to protect the environment and implements charges for disposing pollutants, the importers also have to consider the environmental aspects of the equipment.

\section{Capital resources}

As far as large-scale electricity generating equipment is concerned, the importer's decisions on which country's equipment will be utilized is closely related to the source of capital. If an international financial institution funds a project, the equipment supplier is decided by an international bidding process. If a foreign government or its commercial bank loans the capital, then the project is usually bounded by purchasing equipment from that country.

\section{Traditional trade relationship}

The longer the trade relationship in one country has with other countries, the easier it is to establish good trade and information channels with them. The good trade relations thus play a significant role to the importer's decision, as long as the equipment provided is advanced and reliable.

China's license trade in clean coal technology

Considering from perspectives of companies that acquired technology, the maturity of technology and the timing, China's license trade in clean coal technology has the following characteristics:

Most of entities that acquired technology are large companies. In China, most of medium or small enterprises are the major producers of thermal-energy equipment with high-energy consumption and high emissions. Although their technology level needs to be raised urgently, they are unable to participate decisively in the process of technology transfer. That is because, their limited capital and weak technology strength prevent them from assimilating the new technology effectively. Also, they lack the necessary information and technology transfer experience. Finally, the government's approval procedure and policies for technology transfer do not provide incentives for them to acquire clean technology.

The basic guiding principle for clean coal technology transfer in China is the improvement of outdated equipment and the development of new products and market through technology transfer. Under such guidance and with certain involvement of the government in technology transfer, the companies located in traditional industrial bases, as well as in the southeast areas, where the economic opening up and reform takes place, play a very important role in technology transfer in China.

Prior to 1992 technology transfer was entirely dominated by the government. As the Chinese economy reform progressed, the original mechanisms for technology transfer dominated by the government progressively ended and a new form of technology transfer depending on company's own choices was established in the beginning of 2000. As a result, the transaction activities of technology transfer were restrained to some degree. 
The clean coal technologies that are obtained by China are mature technologies that have been fully commercialized for a long period, are more advanced than the domestic technology and can be quickly applied by the companies.

\section{Clean coal technology transfer through joint ventures}

Acquiring technology is one of the main purposes that China absorbs foreign capital and sets up joint ventures. In the area of clean coal technology, joint ventures have made a contribution to China's clean coal technology transfer, although the contribution is limited. Its main role is to promote equipment imports. Joint ventures involved in clean coal equipment are mainly in the power and heating sector and the manufacture sector.

In the power and heating sector, most joint ventures are cooperated with partners between Hong Kong and Mainland China, which stands $63 \%$ of the contracted-investment enterprises, enterprises run by US and Chinese partners account for $20 \%$, by UK and Chinese partners $8 \%$, with other countries $9 \%$. Joint ventures invested by Hong Kong purchase equipment from both domestic and abroad markets, equipment of joint venture enterprises invested by industrialized countries are mainly purchased from abroad. In the power and heating sector, joint ventures have so far played a limited role in promoting clean coal technology transfer.

In the equipment manufacture sector for clean coal usage, based on the 1995 industry census, joint ventures involved in clean coal equipment manufacturing mainly concentrated in the coal-boiler manufacture industry. There are about 50 joint ventures in the coal-boiler (including power plant boilers) manufacture industry, $90 \%$ of them are small enterprises. The foreign investors for joint ventures of small-scale coal-boiler are mainly from Hong Kong and Taiwan. And what they invest is not technology, but mainly a little capital. The main purpose of the Chinese side is to share joint venture preferential policies. Technology transfer is only the secondary objective of their joint ventures.

\subsubsection{Opportunities for China's Clean Coal Technology}

The review and analysis of equipment imports license trade and joint ventures describe the present situation of China's acquisition of clean coal technology. But what opportunities and obstacles does China have in clean coal technology transfer?

\section{Strengthening of air pollution control}

The Chinese government has lately taken effective measures in order to mitigate the pollutants that are associated with the use of coal (acid rain, particulates, $\mathrm{CO}_{2}$ and other greenhouse gasses). These efforts have produced results that have gained the rest of the world approval as the first positive step towards environmental protection. The strategies and measures adopted by the Chinese government can create new opportunities for China's clean technology acquisition.

In 1998, the Chinese government listed environmental protection as its top priority in infrastructure construction and greatly increased environmental investment. Also because it is difficult to alter the dominant percentage of coals in energy consumption, the 2010 Development Outline for Clean Coal Technology identifies priority fields and specific methods for 
the development of China's clean coal technology. Measures like the above create new prospects for clean coal technology acquisition.

Ongoing economical reform

From the early 1990s, China started reforming its system towards a market economy. By establishing market mechanisms under the law of the competition, companies with no competitive advantages other than a large amount of capital will gradually withdraw from the market. As a result, capital transfers to the more efficient companies. Also, the Chinese companies have to face for the first time pollution charges and penalties for environmental waste. As the protection of the environment and pollution control becomes one of the key factors of government policy, companies can be pushed towards the adaptation of clean coal technology through market forces.

\section{Global environmental cooperation under Kyoto}

With the Kyoto Protocol in 1997, it requires that developed countries have the responsibility to provide financial assistance and transfer environmental technology (including clean coal technology) to developing countries. Even though there has not yet been acceptable progress on the above field, for various political and financial reasons, the efforts that are currently taking place by international organizations lead to the assumption that developing countries will acquire in the end clean coal technology from developed countries in order to mitigate the effects of global $\mathrm{CO}_{2}$ emissions.

\section{Large foreign exchange reserves for Chinese companies}

Before reform of the Chinese foreign trade system, there were severe restrictions into the amount of capital a company could use as foreign exchange for its imports, a critical factor that prevented companies from acquiring new technology from abroad. The reform of the foreign trade system removed these restrictions making the import of new technologies much easier. Also the Chinese government has reduced the import duties for clean coal technologies to very low levels in order to encourage its acquisition.

Increase of the environmental awareness of Chinese public

Environmental awareness of the Chinese public is increasing steadily after 2000 in economically developed city areas like Shanghai and Beijing. It is one of the indirect results of the increased income flow to Chinese citizens and improvement of the quality of life in these areas, when compared with the rural areas of China. The increase of that awareness can be pointed by the publication of environmental monitoring reports at these urban centers. The development of the public environmental awareness has two parallel positive results. It helps the individuals transform their life style particularly in terms of consumption. At the same time it stimulates the evolvement of social pressures, which forces the government to apply new laws and regulations for the protection of the environment. As a result pressure is applied to the companies to improve their environmental behavior with positive results for clean coal technology acquisition.

\subsection{Obstacles in China's Clean Coal Technology Acquisition}

Although there are some positive effects of the acquisition of clean coal technology in China, it should be noted that technology transfer is a two-way economic activity. The willingness, 
conditions of the supplier as well as policies, the availability of funds, resources, and the system for technology transfer in the recipient countries may all become obstacles for clean coal technology acquisition.

\subsubsection{Fewer Joint Ventures in the Field of Clean Coal Technology}

In the equipment manufacture industry for clean coal technology, there are fewer jointventure enterprises, The main reasons are:

1. The market for clean coal equipment is different from the market for other commodities. Its scale is mainly influenced by non-economic factors such as environmental laws and enforcement, environment awareness, and not from technological potency of the investors. It is unlikely that investors will put a large sum of capital, until the uncertainty on China's environmental regulations seizes.

2. Because, China's production volume in the coal power equipment manufacture sector is surplus, with relatively low company profits and intense market competition, foreign investors are not easily attracted to the market. Under current environment standards and resource prices in China, the advantages in energy saving and emission reduction for foreign investors may hardly turn into advantages on the market.

3. Even though the technologies that have been transferred to Chinese companies from foreign companies are advanced for Chinese standards, they are not considered advanced for the rest of the world. Some of the technologies are even considered standard conventional amongst multinational companies. So because the costs of this kind of technologies are relative, foreign companies prefer to sell them through the market than through direct investment. With the improvement of environment law enforcement and intensification of environment sensation, many multinational companies are interested in China's clean coal technology market and have expressed the intent of direct investment.

\subsubsection{Restraints on Technology Transfer Strategies of Multinationals Corporations}

The main obstacle that China faces in its efforts to acquire clean coal technology is the reluctance of foreign companies and organizations to transfer the most up to date technology. The main aim of these companies is their profitability and not the mitigation of environmental effects. As a result their policies focus on exporting equipment and not knowledge as these can lead to the development of local technological equipment. Technology will be exported to China only when it becomes outdated for their standards in order to maintain the dependence. It is a key element of the strategy of monopolizing the market through a monopoly of technology. For instance in the clean coal technology for electricity power boilers, transactional corporations firstly try to exclude the companies from developing countries from the worldwide bidding for power boilers. After they win the bidding they provide the machinery to native companies to manufacture through subcontracting with very competitive prices. As a result these corporations can obtain most of the profits through technological superiority while the companies who actually manufacture the products in the developing countries earn limited profits. Since the international market is structured in this way, 
Chinese companies cannot obtain the latest technology in general and as a result in the field of clean coal as well.

Overall investment by foreign companies in the manufacture sector for clean coal equipment is relatively small. The reasons for less investment from abroad in the manufacture sector for clean coal equipment are non-economic factors such as Chinese environment laws, regulations and standards. They have not yet provided incentives to effectively stimulate the expansion of the market for environment equipment. With the improvement of environmental legislation and enforcement and the promotion of environment awareness in China, some multinational companies in the field of clean coal technology have expressed their interests in investing in China.

\subsubsection{Low Electricity Price in China}

Energy price is an important factor influencing energy consumption and the use of fuel. Before the economic reform took place, energy prices in China were under total government control as elements of the centralized economy. Today it is decided both by market and by government intervention. Even so, China's electricity price still remains relatively low. The low electricity price means that power plants with desulphurization technology have difficulties in recovering the investment costs. As clean coal technologies add more investment cost to the already required desulphurization, the power plants will not be able to recover this cost with the current electricity prices. Therefore, it is considered logical that there is no willingness from the part of the power plants to apply clean coal technologies.

Another factor is that the emissions charge in China is currently lower than the pollution control expenses. This means, that many companies prefer to pay the emission charge rather than applying pollution mitigation technologies. Because of that and of the low electricity prices that prevent the investment recovery from the power plants income, power plants that adopt pollution control equipment often have to stop operation due to high costs.

\subsubsection{Weak Economic Strength of Chinese Companies}

Chinese corporations have always been characterized by very low debt amortization rate. This results to a considerable lack of funds for the development of new technology. Therefore, they are unable to import clean coal technology due to low capital.

In addition to the above, the profits from the implementation of clean coal technologies are mainly long-term and indirect under the current condition in China. There are direct profits as the rise in energy efficiency lowers the production cost but the main part is the environment effects of clean coal technology. The profits of effects can only be realized over a long period of time. Currently, most enterprises attach great importance to the short-term effect while overlooking the positive environment effect achieved through the investment in clean coal technology equipment. Therefore they lack the motive to adopt clean coal technology.

\subsubsection{Strategies for China to Transfer and Develop Clean Coal Technology}

China's strategy for acquiring and developing clean coal technology must not only consider the need of environmental protection and economic growth, but also the long-term target of 
its own independent research, innovation and economic development. China faces the unique problem of environmental deterioration, shortage of resources, and undeveloped clean coal technology while reforming its political and economical system. If the country relies only in domestic supplies for clean coal technologies, the environmental conditions and the shortage of prime resources will be probably be accelerated. On the other hand, if China focuses solely on technology transfer, it will be a hostage to the willingness of transactional corporations and foreign governments, and be unable to develop its own technology. From the above Chinese strategy must try to combine these two aspects in order create its own. Thus the most advisable strategy is to integrate these two aspects so as to establish as soon as possible its own independent system of clean coal technology. To achieve this strategic goal, the following recommendations are proposed:

\section{- Strengthening of Chinese macro-control of technology transfer}

As China is undergoing economic transition, the market mechanism is yet to be perfected. In order to establish its independent innovative system of clean coal technology, and achieve the coordinated development of economic growth and environmental protection, full play should be given to government's macro-control. The following steps should be adopted:

- Define priority channels for clean technology transfer

The priorities of clean coal technology transfer should be changed. Instead of focusing primarily on equipment imports China should make license trading the primary medium for acquiring clean coal technologies. Among various ways of technology acquisition, the priority order should be license trade, foreign direct investment, and equipment imports.

- Exchange the market for new technology Equipment imports should be used as a medium of pressure for the transfer of environmental market and should also provide technological knowledge. In this way China can 'exchange' its market for up to date technologies.

\section{- Support companies in technology acquisition}

The government must support and encourage Chinese companies to implement clean coal technologies with economic and administrative measures. These measures can be in the form of subsidizing clean coal demonstration projects, or on sharing the costs for users of newly imported technology for a period of time.

- Adopt effective measures to integrate technology transfer and domestic research and development The importation of new technologies should not be done in random manner from private companies but under a general plan that must be co-ordinated by the government. In this way, the Chinese companies and research institutions, promoting domestic innovation, can assimilate the technology.

- Take measures to improve the domestic clean coal technology research and development Clean coal technology research and development projects are systematic engineering projects that involve various fields of technology. They require the cooperation of vari- 
ous Chinese universities and technological institutions. Unfortunately, many institutions and universities do not have any knowledge transfers in order to protect their intellectual property and technological advantage. So the required cooperation between different organizations cannot be easily achieved. On top of that the universities and technology institutions tend to lack connection with the industrial sector, meaning that many of the developed projects do not consider the actual capabilities and needs of the industry and become inapplicable.

The most realistic approach to the above problem is if the industry is the one that provides the funding to research institutions in order to answer to specific technological problems. Such a change can promote cooperation and understanding between the different Chinese universities, institutions and companies and increase the applicability of research and development.

\section{Promote the market for clean coal technology by means of law and policy}

The Chinese environmental standards must be raised so that the clean coal technology market can be expanded. The intensification of environmental laws will force companies to adopt clean coal technologies. Also methods of increasing the public environmental awareness should be pursued.

At the same time the pollution charge must be raised and ways of increasing electricity prices must be pursued. The first is crucial to force companies to adopt clean coal technologies, the second is even more important as it will enable companies that apply the technology to survive economically. The prices must not only satisfy the current urge for development but also the needs of future generations.

Finally China should take measures to reduce the lack of legalization of rights for technology development. Legal protection of the intellectual property rights of domestic clean coal technology developers can encourage more research and development projects by institutions and companies.

China encounters the task sustaining its economic growth while adapting measures for environmental protection. This situation is truly unfair when compared with the developed countries that first proceed with their industrial and economic growth after the Second World War and then started establishing regulations for environmental protection. Under these conditions clean coal technology acquisition must not only obey the laws of the market but also be considered in the governmental planning and legislative control.

\subsection{Development of Chinese Power Industry}

In China, electric energy supply reaches $42 \%$ of all end users of energy supply as observed in 2002, which will grow up to about $70 \%$ in 2020 [6]. In order to meet the requirements of rapid development of the Chinese economy, the installed generator capacity has been increasing rapidly. In 1987, the national generation capacity was over 100GW. In April 2000 and May 2004, the total generation capacity reached 300GW and 400GW, respectively. And by the end of 2005, it reached 500GW. In the next decade, the electric load forecasted by the State Grid Co. (SGC) will be about 570GW, 752GW and 966GW in 2010, 2015 and 2020 re- 
spectively, and the corresponding generation capacity will reach 799GW, 978GW and 1211GW.

However because of the large population in China, the electric energy used per capita is still at a low level. In 2002 the kWh per capita of China was about 1,280, which is about the average level for the world in the 1970s. The current average level (2008) in China is 2,500kWh per capita. Therefore the power industry in China will continue to grow rapidly in the future [6]. Figure 13.6 shows a comparison of $\mathrm{kWh}$ per capital worldwide.

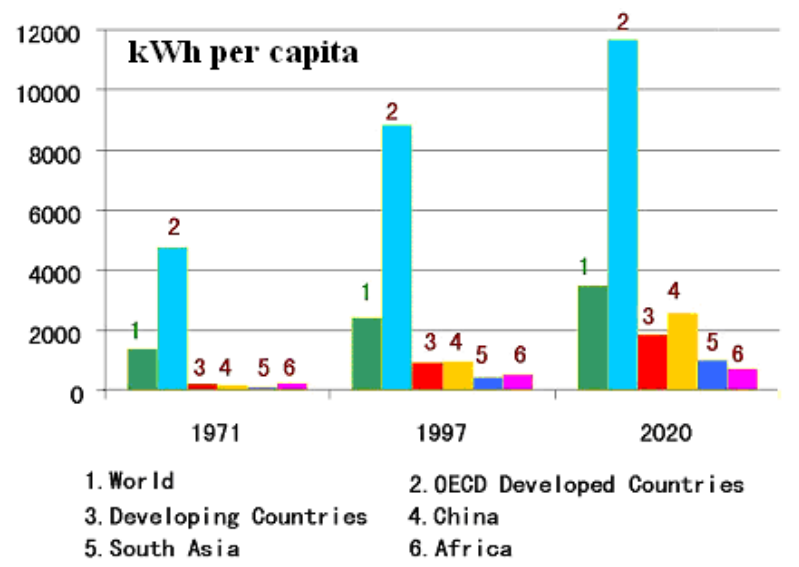

Fig. 13.6 Comparison of kWh per capita

The Chinese power systems have following features

- The load in China is mainly in the South and East of China, while coal and water resources are mainly located in North, Northwest and Southwest of China, which leads to the long-distance heavily-loaded transmission system from west to east and north to south of China.

- Since the resources of petroleum and natural gas are not rich in China and the coal production cannot meet the requirement of power generation, nuclear power plants constructed in the load center are under planning, but the total nuclear power capacity will be no more than $5 \%$ until 2020. In the meantime, the hydropower utilization will be accelerated especially along the Yangtze and Yellow Rivers. In general coal-fired and hydropower will be over $90 \%$ of total capacity in the next 20 years with a small amount of nuclear and other renewable energy.

- Based on the above, China will construct $\pm 800 \mathrm{kV}$ HVDC and $1000 \mathrm{kV}$ UHVAC transmission systems to interconnect the 7 regional power grids of the Northeast, North China, the Northwest, Central China, East China, Chuan-Yu (i.e. the Grid composed of Si-Chuan Province and the City of Chong-qing) and South China in the near future.

- In the meantime, power industry deregulation is underway in China. In its first stage, the traditional vertical monopolistic operation has been converted. The former State Power Co. is now renamed the State Grid Co., SGC. Since the Ministry of Electric Power 
does not exist anymore, the SGC will have the power to plan and construct interregional transmission systems, arrange their bilateral power exchanges and supervise the operation of regional grid companies, etc. (except that the S. China Grid Company is operating independently approved by the State Council for a certain degree of competition in the transmission sector). In the 11 th 5-year Plan (2006-2010), the wholesale mode will be realized in regional power markets. The power utilities will form the power supply companies and join the competition in the power markets. The traditional transmission tasks will be implemented by the grid companies as transcos allowing openaccess as for most power markets in the world.

- In the next decades, the key challenges in Chinese power systems are:

- Optimal planning of nationwide power system interconnection with security consideration.

- Key technology for ultra-high-voltage (UHV) transmission systems.

- Optimal operation of the Chinese power system using advanced technologies (such as computer and communication engineering, applied mathematics and control theory applications, etc.).

- Improvement of power system reliability and power transfer limits to avoid power system blackout and severe stability crises.

- Strengthening power market operation at high-efficiency and encouraging energy saving of end-uses and environment protection to realize sustainable development of the power industry in China.

- To cope with the secure and optimal operation of the complex transmission networks in China, advanced technology will be widely explored, investigated and developed. International collaborations and academic exchanges should be greatly strengthened. It can be foreseen that along with the huge amount of investments entering the power industry, the R\&D funds for power systems will increase rapidly.

\section{Enhancing Demand Side Management}

More attention is paid to enhance load forecasting, optimizing operation mode of the power grid, and concentrating on resources allocation optimization. Backed by the government, demand side management is actively implemented and gives priority to supply electric power needed by the people and key consumers, but also arranges the enterprises to practice peak load shifting so as to relieve the stress of power shortage.

\section{Promoting mechanism reform and innovation of electric power industry}

The mechanism reform and innovation of the electric power industry have been positively promoted in China. China enhances the construction of power markets. Meanwhile, it accelerates the establishment of modern enterprise mechanisms and perfects corporate governance structure.

\subsubsection{The Clean Development Mechanism (CDM)}

It was set up under the Kyoto protocol and requires rich countries to cut their emissions but allows them to do so by buying carbon credits from emission-cutting projects in poor countries. The market in carbon was worth $£ 32 \mathrm{bn}$ in 2007 . It is to be known as cap-and-trade. 
The main provisions of the protocol expire in 2012, so carbon traders are watching closely the tense international negotiations on its successor. The negotiations are scheduled to finish by the end of 2009. It is likely that the US is willing to negotiate a new treaty and support the setting up of an emission market. The UN executive secretary is discussing the idea of 'climate bonds' issued by governments to financial investors. This would be the best way to raise money to pay for efforts to reduce emissions in poor countries.

Such bonds would involve a developing country government setting a national target on emissions or energy, for example a certain amount of renewable energy by 2020. It could count on receiving carbon credits equivalent to this renewable energy under a successor to the Kyoto protocol, which would enable the financial ministry to issue 'climate bonds'. These would raise money from investors based on the promise that they would receive return from the sale of the resulting carbon credits.

This is not possible under the Kyoto protocol because the system for awarding carbon credits requires would-be investors to put money into emission cutting projects, often-small scale and carrying big investment risks. As a result, investment has been relatively small the trading between the rich and poor nations was worth $£ 7 \mathrm{bn}$ in 2007 , compared to $£ 32$ trade in carbon in European Union.

The UN executive secretary believes that government-sponsored climate bonds would reduce investment risk, because government could act as a guarantor, and encourage much greater investment in carbon reduction in the development world. There is recognition that the instruments in place for carbon trading need to continue to be improved. At the moment the trading mechanism under the Kyoto protocol is about small investments in small projects that produce small reductions in emissions.

China has been by far the biggest winner from the Kyoto protocol, receiving tens of billions of dollars in investment to finance low carbon technology [10].

In $2007,73 \%$ of carbon credits projects certified by the United Nations under the protocol were based in China. Under the Kyoto treaty, the 'Clean Development Mechanism' enables rich countries to meet part of the target to cut carbon emissions by funding the development of projects to reduce emission in developing nations. These include wind turbines, capture methane from sewage works and technology used in factory chimneys to destroy harmful industrial gases.

China has benefited most through projects that reduce industrial gases, particularly HFC, a by-product of making refrigerants. Most of the world's factories that produce HFC are in China. Installing equipment to destroy the gas is relatively inexpensive but generates a large volume of carbon credits because the gas is more than 11,000 times more harmful to the climate than carbon dioxide. Most emission-reducing projects now focus on energy efficiency. 


\subsubsection{Market economy development}

In power generation, during the $11^{\text {th }} 5$-year Plan, $300 \mathrm{MW}$ and above thermal plants will account for $50 \%$ of total generation capacity; only $600 \mathrm{MW}$ and above new thermal plants will be allowed to be built; the building of supercritical and ultra-supercritical power units will be encouraged. By 2020, nuclear power will be 40GW.

International ordering and bidding for supercritical, ultra-supercritical and large-scale gas turbine plants, and nuclear power plants will be expanded. 3GW new wind power plants will be installed; more than $70 \%$ of the wind power units will be domestically produced. Domestic production of wind power plants will be accelerated.

During the 11th 5-year Plan, it aims to have: $\mathrm{SO}_{2}$ emission: 12 million-13 million tons/year (10\% reduction from 2005); soot emission: 3 million tons/year (more than $25 \%$ reduction from 2005); coal consumption/kWh: less than 360 g; transmission loss rate: less than $7 \%$; consolidated usage rate of particulates: $70 \%$, etc.

The latent potential of energy conservation and environmental countermeasures in the power generation sector is great; consequently in the future, increased international (governmental and private sector) activity can be anticipated in the concerned sectors.

For transmission infrastructures, during the $11^{\text {th }} 5$-year Plan, it aims to: construct $330 \mathrm{kV}$ and above power grids of length of $7500 \mathrm{~km}$; transformer capacity will reach 360GVA; and the investment will be around 1.5 trillion RMB. There are the State Grid Corporation of China (SGCC) and the China Southern Power Grid (CSPG).

Overseas orders for medium, high and ultra-high voltage transmission $(1,000 \mathrm{kV})$ and transformer facilities will be expanded; and technological collaborations (private sector) will be investigated with respect to network security and stable operations.

The State Electricity Regulatory Commission (SERC) was established in March 2003. Its major responsibilities are to develop laws and regulations; monitor electricity operations; propose tariff and adjustments to governmental pricing authority; investigate any possible violations of laws and regulations; and to supervise the implementation of universal service provisions, etc.

In the power market, the "regulated power rate system" and wholesale power market were introduced. For the retail sector, there was the introduction of the Renewable Energy Law and revision of the Electricity Rate System. Retail prices tend to continually increase. Implementation of the regional power market will be accelerated and it is anticipated that major generators will concentrate on the market due to fierce market competition.

In summary, the future power development plans from 2006 to 2010, may be summarized as follows:

- Proactively work on the development of hydropower

- Implement large-scale expansions of coal-fired thermal power, and upgrade technology 
- Proactive development of nuclear power

- Appropriate introduction of natural gas power generation

- Introduce renewable energy

- Intensify energy conservation, and improve the efficiency of energy utilization

- Realize nationwide interconnection based on the concept of "West-East Power Transmission" and "South-North Power Transmission".

\subsubsection{Electricity Tariffs}

In [9], it reported that the National Development and Reform Commission (NDRC) issued three Measures establish a comprehensive tariff system for electricity in China, covering production, distribution and sale to end users.

The On-Grid Tariff Measures specify different rules for the determination of On-Grid Tariffs before and after the implementation of competitive pricing. Before the implementation of competitive pricing, the On-Grid Tariffs for power generating companies originally under the State Power Corporation were determined by the tariff regulating authority according to cost-compensation principles.

For power plants retained by the State grid enterprises that have an agreed On-Grid Tariff with the tariff regulating authority, their On-Grid Tariffs should remain unchanged. For those who have not agreed to an On-Grid Tariff with the tariff regulating authority, and wholly-owned power generating companies (State grid enterprises or non-State grid enterprises) and other power plants for which On-Grid Tariffs have not been agreed or confirmed by the tariff regulating authority, their On-Grid Tariffs shall be determined by the tariff regulating authority on the basis of the economic life span of the project, according to the principles of reasonable compensation, reasonable actual benefits and with consideration given to the tax payable under PRC law.

The On-Grid Tariff Measures provide that pricing systems such as peak and valley pricing, seasonal pricing etc. are to be introduced gradually. When the fluctuation in fuel prices is fairly large, the On-Grid Tariffs may be linked to the fuel price as long as the tariffs also reflect demand and supply.

After the implementation of competitive pricing and the establishment of competitive regional power markets, the On-Grid Tariffs of electricity generation companies which participate in the competitive market shall principally consist of two components: the capacity charge, which is to be determined by the tariff regulatory authority, and the energy charge, which is to be determined by market competition. The On-Grid Tariffs of electricity generation companies that do not participate in the competitive market will be determined by the tariff regulatory authority on basis of their economic life span.

The On-Grid Tariff Measures also deal with electricity generation companies with direct foreign investment. If such companies were constructed prior to 1994 and executed their power purchase contracts prior to 1994, or were established in or after 1994 with State Council approved undertakings regarding electricity tariff or the rate of investment return, new nego- 
tiations may be conducted in order to allow them to operate as much as possible in accordance with the new system.

The Transmission and Distribution Tariff Measures define "transmission and distribution tariffs" as the common term used for tariffs charged by State grid enterprises for the provision of access systems, inter-grid connection, electricity transmission and sales services.

The transmission and distribution tariffs are to be fixed by the government. The basis of the tariffs shall be considerations such as reasonable compensation of cost, reasonable determination of returns, lawful inclusion of taxes and fair sharing of the burden.

The Transmission and Distribution Tariff Measures distinguish between tariffs for electricity transmission and distribution services via public grids, tariffs for dedicated services and tariffs for ancillary services provided by an electric power enterprise. The Transmission and Distribution Tariff Measures detail how the various tariffs are to be determined.

The End-User Tariff Measures define the term "Electricity Tariffs" as the tariffs at which State grid enterprises sell electricity to end users.

The government fixes electricity tariffs. The tariffs shall be determined with consideration to the fair sharing of the burden, the efficient adjustment of the demand for electricity, and public policy objectives. The government will create a mechanism to link Electricity Tariffs to On-Grid Tariffs.

Electricity Tariffs are made up of four elements, the electricity purchase cost, electricity loss during transmission, electricity transmission price, and cost of government fund.

The End-User Tariff Measures aim to reform the various classes of tariff for end users into three categories: residential electricity; electricity used in agricultural production; and electricity used in industry, commerce or for other purposes. The tariff for each category is fixed per voltage class. For residential electricity and electricity used in agricultural production, the Electricity Tariff is calculated per kilowatt-hour. For industrial, commercial or other electricity users who have receiving transformers with a capacity of $100 \mathrm{kVA}$ or more or who have electrical equipment with an installed receiving capacity of $100 \mathrm{~kW}$ or more, the Electricity Tariff comprises the kWh-hour tariff (calculated on the basis of actual use) and the basic electricity tariff (based on the user's consumption capacity).

It was reported in [11], because of the increasing cost of coal (the country's main source of energy for electricity production), the government in 2004 approved the mechanism linking coal and power prices. This allowed electricity prices to shift in line with coal price increases. Under the mechanism, if the price of coal rose by more than $5 \%$ in a six-month period, electricity prices could be adjusted. With the mechanism, $70 \%$ of coal price increases are transferred to end-users. Power generation firms bear the remaining 30\%. However, electricity prices have not yet been fully linked to the market. The government will do more work on the electricity pricing system in order to link it more closely to movements in raw materials. 
China is trying to adjust its power mix, hoping that clean power will make up at least $35 \%$ of the entire supply in 2010.

Under the Renewable Energy Law, which took effect in 2008, the Chinese Government announced rules for setting prices on electricity generated from wind, solar and biomass. As reported in China Daily in July 2006, power generators that use renewable fuels are allowed to charge higher rates to power grid operators than coal-fired plants, with the additional cost split among grid operators and partly passed on to retailers.

\subsection{R\&D on Power System Sponsored Funds} by National Science Foundation China (NSFC)

In China R\&D funds support power system projects through several ways. In the State Council, there are commissions that will support power system R\&D projects relevant to their functions, including the State Development and Reform Commission, the State Economy and Trade Commission, and the State Electric Power Surveillance Commission.

The NSFC was founded in February 1986 with approval of the State Council, which is aiming at promoting and supporting basic research and key applied research in China. Now NSFC employs less than 200 staff members with over $90 \%$ as professionals at an average age of 42 . It has established a solid system to make strategic plans on key and basic research, evaluate various proposals, and assess R\&D outputs strictly, fairly and scientifically. Since its foundation, the budget of NSFC has increased dramatically from 80 million RMB in 1986 to 2 billion RMB in 2004, about 25 times higher. The projects sponsored by NSFC are now classified into the categories of major projects, key projects and general projects to be funded at different strengths and scales. Besides, special funds are launched for outstanding young investigators to promote their R\&D excellence and for international exchange and collaboration.

In the traditional electrical engineering area (i.e. heavy-current area mainly on power engineering), 6 key projects were sponsored during 1996-2000 at 5.1 million RMB in total; while in 2000-2005, 6 major and key projects were sponsored at 11.3 million RMB in total. The NSFC sponsored general projects increased from 40 projects and 7.6 million RMB in 2001 to 98 projects and 26.4 million RMB in electrical engineering subjects in 2006.

The NSFC major and key projects in electrical engineering focus on the significant R\&D areas in power engineering, such as FACTS devices (TCSC) design, development, operation and simulation, non-linear robust control theory and its applications in power systems, fundamentals of power markets, super-conductor technology and its applications in power systems, basic theory and key technology for power system security control, etc. A major project on key technology for HV AC/DC power systems is in the planning stage.

In a key project jointly sponsored by NSFC and SGC, EPRI-China has successfully designed and constructed a prototype of TCSC. The TCSC was installed on a $220 \mathrm{kV}$ AC transmission line in the Gansu Provincial Grid and commitioned in December 2004. The compensation 
level was $50 \%$ of line reactance with the capacity at 95.4 MVAr, which increased the transmission capacity by $33 \%$.

Although the funds for power engineering is about $1 / 20$ of all funds for engineering and material science, and 1/100 of overall NSFC funds, it plays an important role to give preliminary support on basic and fundamental research and lay a solid foundation for further supports from industry. Actually some key projects are sponsored by the power industry in parallel, such as the project on multi-infeed HVDC transmission system reliability and control, etc. In addition, other departments of NSFC (such as the information department, etc.) will also sponsor multi-discipline projects related to the applications of advanced technologies in power systems.

It should be mentioned that in parallel with NSFC, there are two National Key and Basic Research Projects (so-called '973' projects) on power engineering. One is "Vital Research on Collapse Prevention and Optimal Operation of Large Power Systems in China" (1999-2003) and the other is "Fundamental Research on Improving the Reliability of Large-scale Interconnected Electric Power System" (2004-2008). The project funds are 50 million RMB and 30 million RMB, respectively. The nationwide experts of power engineering are working together for the projects and have made great contributions to the Chinese power industry.

The facts mentioned above show clearly the impacts of fast development of Chinese power industry on power system R\&D. The provincial governments, power companies and manufactures are all actively supporting $R \& D$ projects in power engineering so as to get benefits from the outputs.

\subsection{Conclusions}

An insight into the power generation and transmission infrastructure in China has been given in this chapter. It is clear that the future is full of uncertainty but there are many fronts that have been developed and advanced to minimize the risks occurred.

The coal-fired energy system can evolve in ways consistent with sustainable development objectives if public policies guide a high rate of innovation toward clean coal technologies. On the basis of present knowledge, it is possible to identify and describe advanced clean coal technologies that meet sustainable development objectives at reasonable cost.

Due to the enormous size of China's population, the country's coal reserves per capita are insufficient, and consuming a large quantity of coal causes tremendous environmental pressures. All these factors mean that, in order to ensure energy supplies and to achieve sustainable development objects, energy efficiency must be a priority.

It is believed that for many years to come, coal will still be the most important source for electricity generation. China's great potential market for clean coal technology is unquestionable. However, it must also be noted that there are many obstacles to clean coal technology acquisition in China. If no enforceable system and effective policy mechanisms are established, such potential will be unlikely to be turned into real opportunities. 


\subsection{Acknowledgements}

Loi Lei LAI, Professor and Head of the Energy Systems Group, School of Engineering and Mathematical Sciences, City University London, UK has coordinated this Chapter. Thanks are due to Long Zhou and Ms Yingnan Ma of the Energy Systems Group at City University London for the detailed preparing this Chapter. Copyright release by the IEEE is very much appreciated.

\subsection{References}

[1] Yin Yonghua, "Electric power system in China: History of development, present status \& future perspective", IEEE Power Engineering Society General Meeting, Tampa, June 2007.

[2] Yinbiao Shu, 'Current Status and Development of National Grid in China,' IEEE T\&D Conference, 2005, Dalian, P R China, August 2005.

[3] Yuan Maozhen, 'South China HVAC and HYDC Hybrid Grid: Development and Challenges,' IEEE T\&D Conference, Dalian, P R China, August 2005.

[4] Yusheng Xue, "Towards space-time cooperative defense framework against blackouts in China", IEEE Power Engineering Society General Meeting, Tampa, June 2007.

[5] Qixun Yang and Bi Tianshu, "WAMS implementation in China and the challenges for bulk power system protect", IEEE Power Engineering Society General Meeting, Tampa, June 2007.

[6] China's Energy Development Strategy and Policy Study, Development Research Center of State Council P.R. China, 2004, p.197.

[7] South China Morning Posts, April 2008.

[8] Shuyong Chen, Feili Huang, Baohui Zhang, Yixin Ni, Libao Shi and Zheng Xu, "Fast development of Chinese power industry and its impacts on power system R\&D outputs", IEEE Power Engineering Society General Meeting, Tampa, June 2007.

[9] China: Electricity Tariff Reform, August 29, 2005 - Hong Kong http://www.hg.org/articles/article_805.html

[10] Fiona Harvey, Chinese reaps biggest Kyoto rewards, Financial Times, 27 May 2008.

[11] China Daily July 1, 2006, http:/ / www.china.org.cn/english/2006/Jul/173343.htm http://www.fossil.energy.gov/international/International_Partners/China.html 


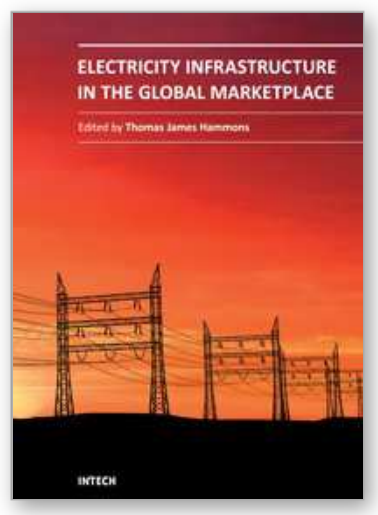

\author{
Electricity Infrastructures in the Global Marketplace \\ Edited by
}

ISBN 978-953-307-155-8

Hard cover, 802 pages

Publisher InTech

Published online 27, June, 2011

Published in print edition June, 2011

This book discusses trends in the energy industries of emerging economies in all continents. It provides the forum for dissemination and exchange of scientific and engineering information on the theoretical generic and applied areas of scientific and engineering knowledge relating to electrical power infrastructure in the global marketplace. It is a timely reference to modern deregulated energy infrastructure: challenges of restructuring electricity markets in emerging economies. The topics deal with nuclear and hydropower worldwide; biomass; energy potential of the oceans; geothermal energy; reliability; wind power; integrating renewable and dispersed electricity into the grid; electricity markets in Africa, Asia, China, Europe, India, Russia, and in South America. In addition the merits of GHG programs and markets on the electrical power industry, market mechanisms and supply adequacy in hydro-dominated countries in Latin America, energy issues under deregulated environments (including insurance issues) and the African Union and new partnerships for Africa's development is considered.

Thomas James Hammons (Fellow IEEE 1996) received the B.Sc. degree in Engineering (1st Class Honors), and the DIC, and Ph.D. degrees from Imperial College, London, UK He is a member of the teaching faculty of the School of Engineering, University of Glasgow, Scotland, UK. He was Professor of Electrical and Computer Engineering at McMaster University, Hamilton, Ontario, Canada in 1978-1979. He is the author/co-author of over 440 scientific articles and papers on electrical power engineering and is Editor of a book on Renewable Energy that was published by INTECH in December 2009. He has lectured extensively in North America, Africa, Asia, and both in Eastern and Western Europe.

Dr Hammons is Past Chair of the United Kingdom and Republic of Ireland (UKRI) Section IEEE and Past Chair of International Practices for Energy Development and Power Generation of IEEE. He is also a Past Chair of the IEEE PES Task Force on harmonizing power-engineering standards worldwide and Past Permanent Secretary of the International Universities Power Engineering Conference. He is a Chartered Engineer (CEng) and a registered European Engineer in the Federation of National Engineering Associations in Europe.

\title{
How to reference
}

In order to correctly reference this scholarly work, feel free to copy and paste the following:

T. J. Hammons (2011). Developments in Power Generation and Transmission Infrastructures in China, Electricity Infrastructures in the Global Marketplace, (Ed.), ISBN: 978-953-307-155-8, InTech, Available from: http://www.intechopen.com/books/electricity-infrastructures-in-the-global-marketplace/developments-in-powergeneration-and-transmission-infrastructures-in-china 
open science / open minds

InTech Europe

University Campus STeP Ri

Slavka Krautzeka 83/A

51000 Rijeka, Croatia

Phone: +385 (51) 770447

Fax: +385 (51) 686166

www.intechopen.com
InTech China

Unit 405, Office Block, Hotel Equatorial Shanghai

No.65, Yan An Road (West), Shanghai, 200040, China

中国上海市延安西路65号上海国际贵都大饭店办公楼 405 单元

Phone: +86-21-62489820

Fax: +86-21-62489821 
(C) 2011 The Author(s). Licensee IntechOpen. This chapter is distributed under the terms of the Creative Commons Attribution-NonCommercialShareAlike-3.0 License, which permits use, distribution and reproduction for non-commercial purposes, provided the original is properly cited and derivative works building on this content are distributed under the same license. 